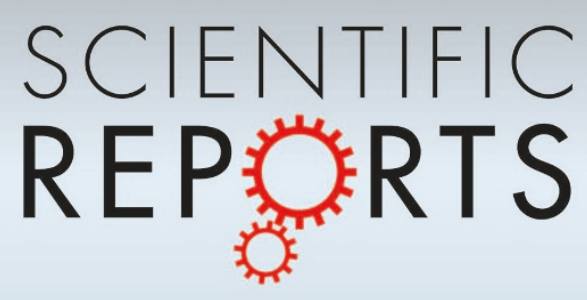

OPEN

SUBJECT AREAS:

PHYSICAL

OCEANOGRAPHY

PROJECTION AND PREDICTION

Received

14 July 2014

Accepted

10 October 2014

Published

29 October 2014

Correspondence and requests for materials should be addressed to

J.Z. (jieshun@cola. iges.org)

\section{Salinity anomaly as a trigger for ENSO events}

\author{
Jieshun Zhu', Bohua Huang ${ }^{1,2}$, Rong-Hua Zhang ${ }^{3}$, Zeng-Zhen $\mathrm{Hu}^{4}$, Arun Kumar ${ }^{4}$, \\ Magdalena A. Balmaseda ${ }^{5}$, Lawrence Marx' \& James L. Kinter III',
}

${ }^{1}$ Center for Ocean-Land-Atmosphere Studies, George Mason University, Fairfax, Virginia, USA, ²Department of Atmospheric, Oceanic, and Earth Sciences, College of Science, George Mason University, Fairfax, Virginia, USA, ${ }^{3}$ Key Laboratory of Ocean Circulation and Waves, Institute of Oceanology, Chinese Academy of Sciences, Qingdao, China, ${ }^{4}$ Climate Prediction Center, National Centers for Environmental Prediction/NOAA, College Park, Maryland, USA, ${ }^{5}$ European Centre for Medium-Range Weather Forecasts, Reading, United Kingdom.

According to the classical theories of ENSO, subsurface anomalies in ocean thermal structure are precursors for ENSO events and their initial specification is essential for skillful ENSO forecast. Although ocean salinity in the tropical Pacific (particularly in the western Pacific warm pool) can vary in response to El Niño events, its effect on ENSO evolution and forecasts of ENSO has been less explored. Here we present evidence that, in addition to the passive response, salinity variability may also play an active role in ENSO evolution, and thus important in forecasting El Niño events. By comparing two forecast experiments in which the interannually variability of salinity in the ocean initial states is either included or excluded, the salinity variability is shown to be essential to correctly forecast the 2007/08 La Niña starting from April 2007. With realistic salinity initial states, the tendency to decay of the subsurface cold condition during the spring and early summer 2007 was interrupted by positive salinity anomalies in the upper central Pacific, which working together with the Bjerknes positive feedback, contributed to the development of the La Niña event. Our study suggests that ENSO forecasts will benefit from more accurate salinity observations with large-scale spatial coverage.

$\mathrm{T}$ he quality of forecasts of El Niño and the Southern Oscillation (ENSO) has clearly improved since the initial attempts ${ }^{1}$, when the theoretical understanding of ENSO was first applied as the scientific basis of coupled ocean-atmosphere prediction. The reigning paradigm for ENSO dynamics is attributed to Bjerknes ${ }^{2}$, who was the first to suggest a positive ocean-atmosphere feedback. According to Bjerknes, an El Niño (La Niña) event develops when an initial positive (negative) sea surface temperature anomaly appears in the equatorial eastern Pacific. This weakens (strengthens) the surface trade wind that in turn drives ocean circulation changes and reinforces the initial sea surface temperature (SST) anomaly.

In the first experimental ENSO forecast, Cane et al. ${ }^{1}$ demonstrated the importance of the initial tropical upper ocean heat content anomaly in successfully predicting the future ENSO evolution. Following the pioneering work of $\mathrm{Wyrtki}^{3}$, they emphasized that oceanic meridional heat transport replenishes the heat content in the equatorial Pacific and preconditions the major El Niño events. These arguments later led to the development of theories of the delayed oscillator ${ }^{4,5}$ and the discharge-recharge oscillator ${ }^{6}$. According to these theories, subsurface anomalies in the ocean thermal state related to thermocline displacements are precursors for ENSO evolution and accurately specifying the initial thermal state of the upper tropical ocean is essential for prediction.

However, knowledge of the heat content alone may not be sufficient for predicting ENSO events on the seasonal time scale. This may be because the favorable time window for triggering an ENSO event is narrow, occurring only in spring and early summer ${ }^{7}$. For example, if warm water has built up in the western Pacific in boreal spring but an El Niño event is not initiated at that time, it might not be until the next spring that an event occurs. Therefore, other atmosphere/ocean conditions may also play a critical role in determining whether a warm or cold event occurs in a given year. For example, the occurrence, intensity and extent of intraseasonal wind bursts in boreal spring are important factors ${ }^{8}$.

In addition of influence of aforementioned precursors for ENSO development, in this study we explore the effect of near surface salinity in the equatorial Pacific. Because salinity affects the density of ocean water, it plays a role in maintaining the mean and low-frequency variability of Pacific climate through its effects on the horizontal pressure gradients, stratification, and the equatorial thermocline ${ }^{9-16}$. In the tropical Pacific, particularly in the western Pacific warm pool (WPWP), however, salinity variability has been viewed mainly as a passive response to ENSO states. During El Niño (La Niña), sea surface salinity decreases (increases) in the western and central 
equatorial Pacific, as a result of zonal advection of low (high) salinity water by anomalous eastward (westward) surface currents, and to a lesser extent as a result of a rainfall excess (deficit) associated with atmospheric convection and warm water displacements ${ }^{11,17,18}$. It has been suggested that the barrier layer in the western Pacific warm pool resulting from the salinity stratification may help the heat buildup during an El Niño event ${ }^{12,13,16}$, and the salinity significantly contributes to the surface dynamic height anomalies in the western and south-central Pacific ${ }^{19}$. To what extent these salinity variabilities influence the ENSO evolution is not yet clear.

Other studies suggest that surface salinity may have the potential to influence ENSO prediction ${ }^{20-22}$. Zhao et al ${ }^{23,24}$ recently show that their seasonal forecasts appear sensitive to improved assimilation of subsurface temperatures and salinity. Aside from these few exceptions, the role of salinity in seasonal forecasts has traditionally been neglected. For instance, salinity was neglected in all intermediate coupled ENSO forecast models ${ }^{1,25}$ and statistical ENSO forecast models (see examples $\mathrm{in}^{26}$ ). This is partly due to the historical lack of salinity observations and partly due to the assumption that the effect is small. In this study, we provide direct evidence of the effect of interannually varying salinity on ENSO evolution and its prediction. It will be shown that the salinity anomaly on the eastern edge of WPWP in spring 2007 played an active dynamical role in promoting development of La Niña conditions later in the year. We examine this effect by producing two sets of forecasts using CFSv2 ${ }^{27}$, the current operational forecast system for seasonal-to-interannual climate at the National Centers for Environmental Predictions (NCEP). The CTL forecasts are initialized from realistic ocean states. In the noS forecasts, all settings are the same as CTL, except that the initial salinity is set to the climatological value (see Methods). The differences between the two forecasts are clearly due to the salinity variability.

Figure 1 shows the observed and predicted Niño-3.4 $\left(5^{\circ} \mathrm{S}-5^{\circ} \mathrm{N}\right.$, $120^{\circ} \mathrm{W}-170^{\circ} \mathrm{W}$; see ${ }^{28}$ ) SST anomalies during 2001-2010. In forecasts produced for years prior to 2001, CTL and noS are not significantly different (Supplementary Fig. S1). For example, neither CTL nor noS predicted the 1982/83 El Niño event well, but they both captured the historically strongest 1997/98 El Niño event with a similar skill level. This is probably because most sub-surface salinity measurements are from the Argo floats deployed since $2000^{29}$, even though it can be also potentially caused by other possible factors. During 2001-2010, several El Niño and La Niña events occurred, including three moderate warm events (2002/03, 2006/07 and 2009/10) and one moderate cold event (2007/08). For the 2006/07 and 2009/10 cases, both CTL and noS were moderately skillful forecasts. For the 2002/03 El Niño event, both CTL and noS generally predicted it well, although CTL was slightly better in terms of amplitude. The most notable difference between CTL and noS was found in the 2007/08 La Niña event. The event was remarkably well predicted by CTL but completely missed by noS. This tremendous difference suggests that the interannually varying salinity missing from the initial state of noS played an important role in the evolution of 2007/08 La Niña, beginning in late spring. This finding is consistent with a previous study ${ }^{15}$ based on Argo data, which identified significant interannual salinity variability associated with the 2007/08 La Niña event.

Forecasts of the SST and sea surface salinity (SSS) anomalies along the equator starting from April 2007 are shown in Fig. 2 for both CTL and noS. In the observations (Fig. 2c), during the first three months (April-June 2007), negative SST anomalies appear in the eastern Pacific, coincident with positive SSS anomalies in the central Pacific. Beginning in July, the negative SST anomalies extend to the central Pacific, and in the following months develop into a mature La Niña state that peaks in winter. Meanwhile, positive SSS anomalies start to appear and increase in magnitude in the western Pacific, which happens mostly as a response to the La Niña condition $^{11,17,18}$.

The evolution of these SST and SSS anomalies (Fig. 2c) was well predicted by CTL. However, no such evolution of these SST and SSS anomalies was produced in the noS forecast (Fig. 2b). As expected from our experimental design, the positive SSS anomalies in the central Pacific do not exist during April-June 2007 in the noS prediction. Although the negative SST anomalies are present in the eastern Pacific during this period, as a result of the persistence of the initial state, the initial SST signal in noS did not develop further, in contrast to CTL. Consequently, the observed positive SSS anomalies in the western Pacific are not well predicted in subsequent months.

A more detailed view of the spatial distribution of the evolution of the SST anomaly for the first six months is provided in Supplementary Fig. S2. There is a pronounced difference between observations/CTL and noS in the SST change from June to July, the early developing phase of the anomalous event. In particular, during April-June 2007, negative SST anomalies were present in the eastern Pacific in both observations and the two predictions. Although these SST anomalies weaken in the eastern Pacific over the next few months in both sets of predictions, the SST anomalies in noS weakens much faster, especially from May to June. Beginning in July, the negative SST signal grows quickly in observations and CTL and extends to the central Pacific, developing into a well-defined La Niña event in August and September. This development is apparently a result of the positive feedback ${ }^{2}$ between SST and the overlying wind stress that was triggered in early summer. In contrast, the negative SST signal decays dramatically in noS from July onward and becomes almost invisible during the following months, probably because the weaker SST anomalies in June are not sufficient to trigger the Bjerknes positive feedback.

How the initial salinity states affect the prediction of 2007/08 La Niña can be illustrated by comparing the evolution of subsurface conditions between CTL and noS (Fig. 3; see also Supplementary Figs. S3 and S4 for the first six months forecast starting from April 2007). At the beginning (i.e., April 2007), the same intense cold anomalies tilt upward from west to east along the thermocline in both the CTL and noS predictions, which emerge at the surface in the eastern Pacific (Supplementary Fig. S2). Meanwhile, in the CTL pre-

\section{Predicted and observed Nino-3.4 index: 2001-2009}

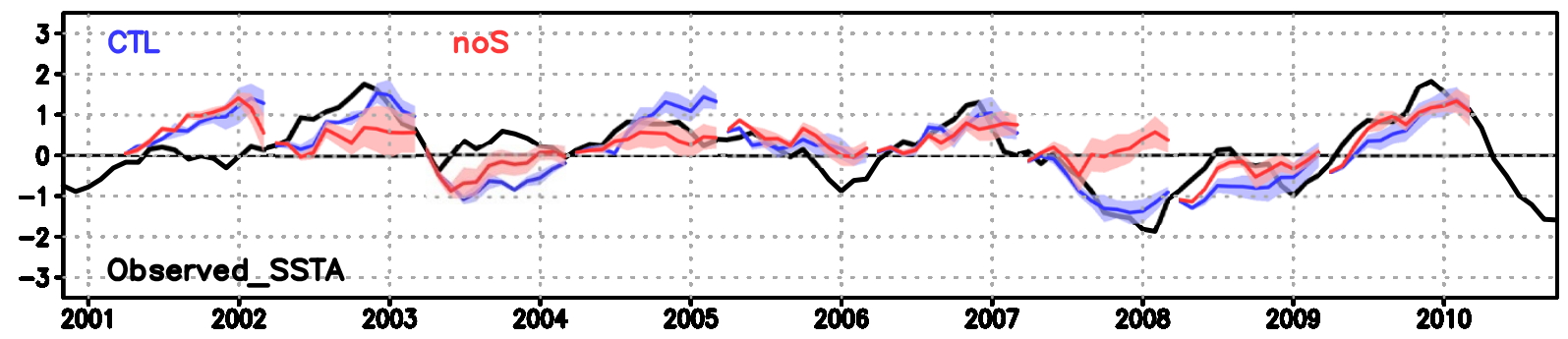

Figure $1 \mid$ Niño-3.4 SST anomalies $\left({ }^{\circ} \mathrm{C}\right)$ for the period 2001-2010. SST anomalies are shown in black, blue, and red curves for observations, CTL and noS, respectively. For forecasts, solid curves (shaded areas) represent the ensemble mean (ensemble spread). 


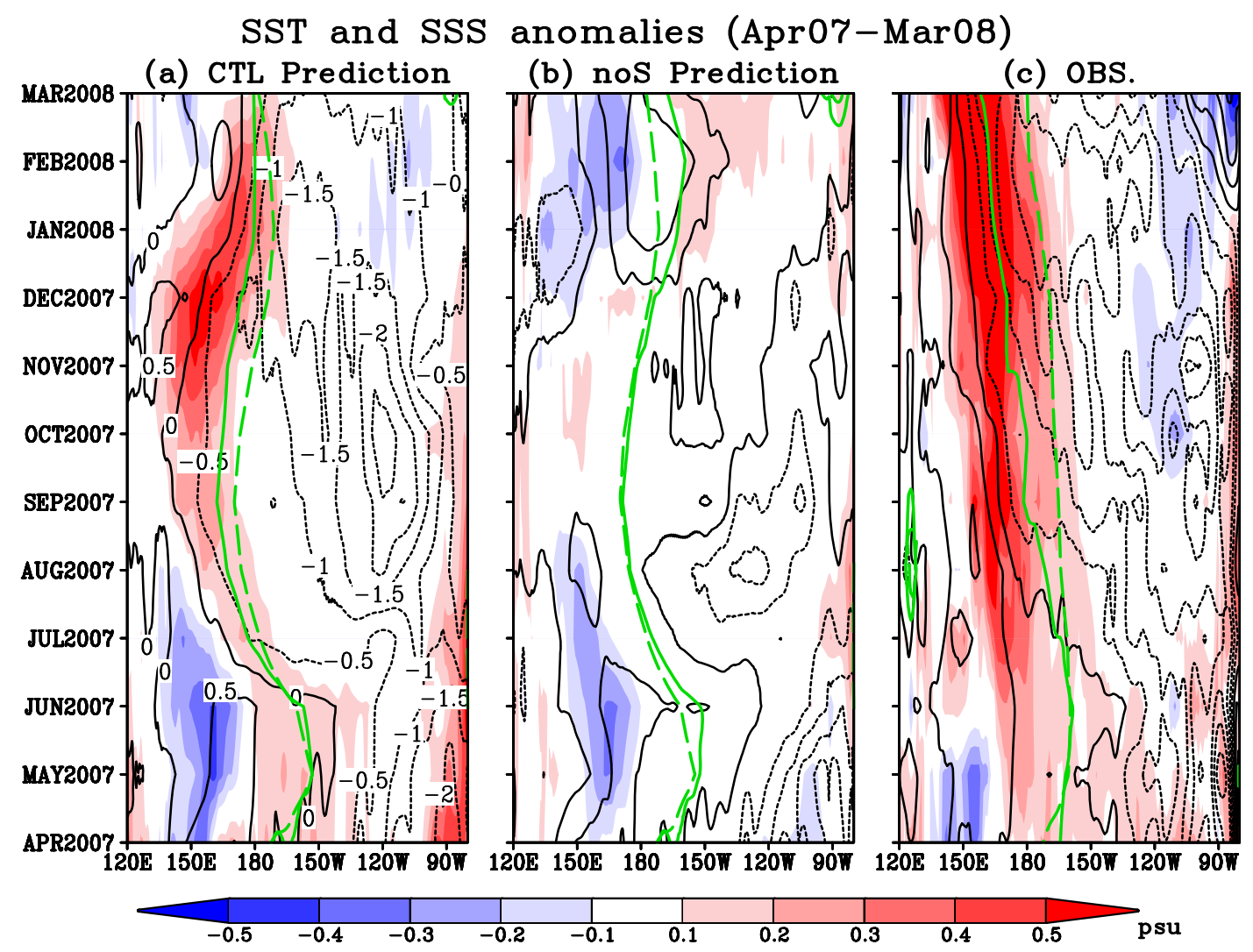

Figure $2 \mid$ Longitude-time sections of anomaly fields. SST anomalies (contour, ${ }^{\circ} \mathrm{C}$ ) and SSS anomalies (shading, psu) along the equator (averaging over $2^{\circ} \mathrm{S}-2^{\circ} \mathrm{N}$ ) during Apr. 2007-Mar. 2008 from (a) CTL prediction (ensemble mean), (b) noS prediction (ensemble mean) and (c) observations. The overlaid green contours are the $28^{\circ} \mathrm{C}$ isotherms with solid (dashed) one for the event year (the climatologies based on 1982-2009).

diction, a positive salinity anomaly is present in the central Pacific, which extends to levels deeper than $50 \mathrm{~m}$. This positive salinity anomaly is the major difference between the CTL and noS predictions in their initial salinity states, which persists in the near-surface layers from April to June 2007 in CTL (see Supplementary Fig. S3). There is also another salinity difference between the CTL and noS predictions appearing in the far western Pacific characterized by a negative salinity anomaly in CTL, which, however, is a response to the cold state in the eastern Pacific and immediately emerges in the second month of the noS prediction (see Supplementary Fig. 4). Thus, the latter salinity difference is unlikely to be the cause of the difference in the CTL and noS forecasts of the 2007/08 La Niña event.

Generally, the persistent positive salinity anomaly in the central Pacific increases the local near-surface density (see Supplementary Fig. S6) and destabilizes the upper ocean, which enhances the vertical mixing at the base of the mixed layer, cooling the upper ocean ${ }^{14,15}$. This counters the decay of the initial subsurface cold states during the first three months (April-June 2007) in the CTL prediction (see Fig. 3, or Supplementary Fig. 3). As a result, the anomaly decay rate is clearly lower in CTL than in noS (see Supplementary Fig. S5). For instance, although the subsurface cold state along the tilted thermocline weakens substantially beginning in April and becomes less organized by June in the noS prediction, it remains robust in the CTL prediction. In other words, the tendency of the subsurface cold condition to decay is interrupted by the near-surface positive salinity anomalies in the CTL prediction. During the following July and August, the subsurface cold anomaly is slightly strengthened in noS, possibly by the transport of anomalously cold water from the off-equatorial regions. However, the difference of the subsurface cold state between the CTL and noS predictions becomes larger than that during April-June, which is due to the Bjerknes positive feedback in CTL. In September, a mature La Niña event is fully developed in CTL as a result of this positive feedback, with the whole upper ocean being anomalously cold. In noS, however, the subsurface cold state decays further, and there are no systematic subsurface signals.

From the above analysis, it can be concluded that salinity can play a very important role in ENSO SST variability. By looking at the composite figures of temperature (density and salinity) based on cases of low salinity anomaly on the eastern edge of WPWP (figures not shown), it is also noted that the salinity effect exhibits an asymmetry with larger effects happening during cold periods than warm periods. In the case of the 2007/08 cold event, initial salinity anomalies in the spring season seem to be crucial for triggering the initial development. It is helpful that current forecast systems, given proper initialization, are able to predict salinity, as revealed by the SSS anomalies predictive skill during the more recent period of our experiments (1995-2009) (Supplementary Figs. S7 and S8), when the amount of salinity observations is clearly larger than before. This 15-year period is sufficient to construct a relatively large forecast sample. As shown, at least at the $0 \sim 3$ month lead times, salinity initialization in CTL clearly enhances prediction skill, relative to noS. Any skill in predicting SSS in noS can be attributed to the response, for example, to SST states in the eastern Pacific. Furthermore, skillful SSS predictions in CTL (defined as having correlation higher than 0.5 ) along the whole equatorial Pacific at $0 \sim 2$ month lead times (Supplementary Fig. 8a) can be critical for ENSO prediction beginning in spring.

Accurate salinity initial conditions may be more important for predictions beginning in and during spring when the air-sea coupling is weaker than in other seasons and the predictability is generally lower (i.e., the spring predictability barrier). The prediction starting from April 2007 presented here supports this hypothesis. Thus, better utilization of salinity data and more salinity observations may have potential to lessen the spring predictability barrier problem. On 


\section{Temp. (contour) and Salinity (shading) anomalies}

Apr07

Jun07
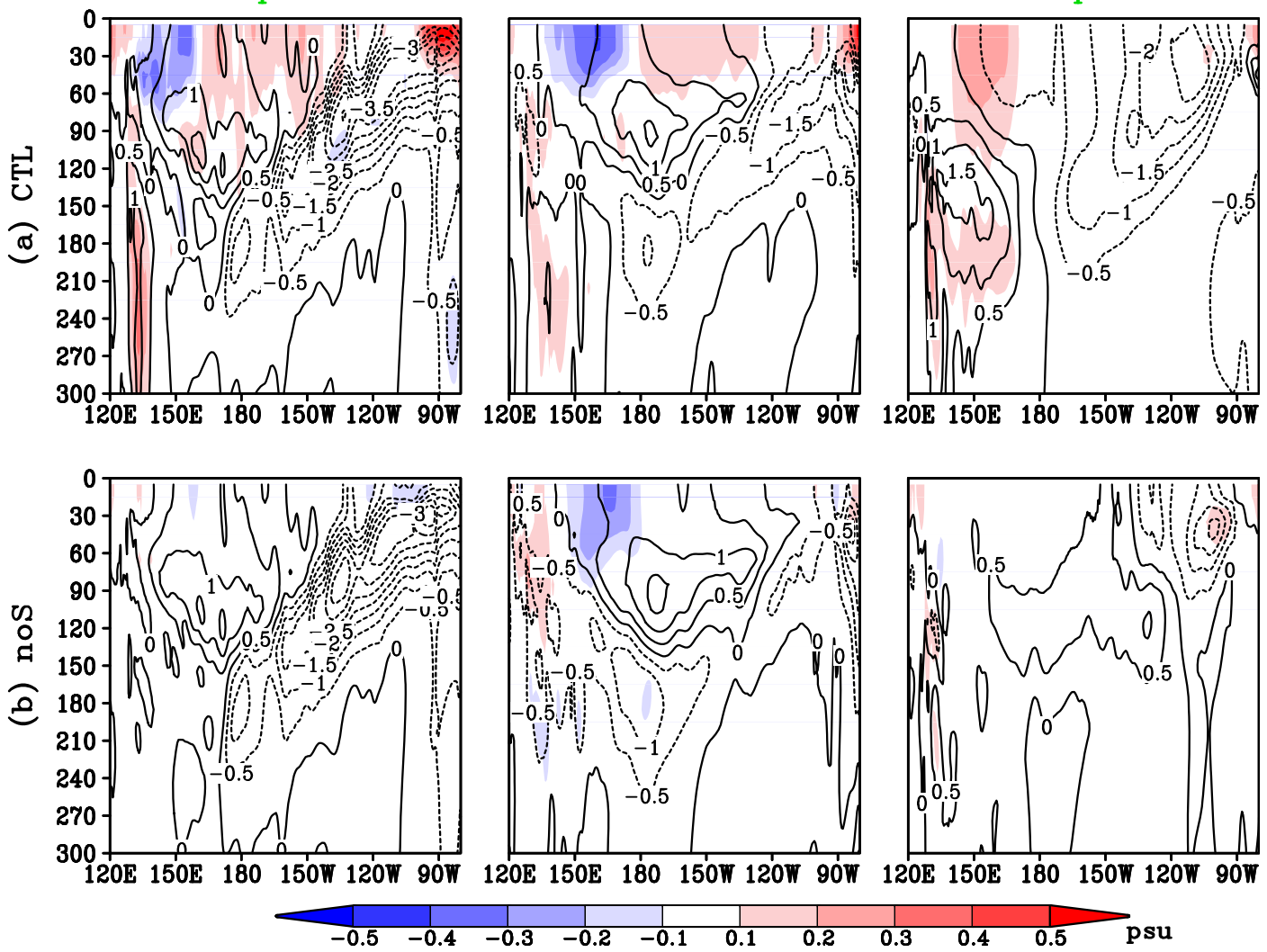

Figure 3 | Longitude-depth sections of anomaly fields. Ocean temperature anomalies (contol
equator (averaging over $2^{\circ} \mathrm{S}-2^{\circ} \mathrm{N}$ ) in (a) CTL and (b) noS during Apr., Jun. and Sep. 2007.

the other hand, as deduced from Fig. 2 for the 2007/08 La Niña case, the amplitude of such salinity variability may not be so high, one order of magnitude smaller compared to the seasonal variations within the WPWP. This indicates that more data with large-scale spatial coverage and accurate observations of the salinity field are required. While accuracy is still a very important issue for satellite missions, more in-situ observations are definitely needed to improve such accuracy, and potentially, for better forecasts. In summary, our results suggest that ENSO forecasts will benefit from more observations of salinity, such as the deployments of Argo floats and the gridded satellite SSS dataset provided by satellite missions including SMOS and Aquarius/SAC-D.

\section{Methods}

NCEP Climate Forecast System, version 2 (CFSv2). The forecast model used in this study is the National Centers for Environmental Predictions (NCEP) CFSv2 $2^{27}$. CFSv2 has been the operational forecast system for seasonal-to-interannual prediction at NCEP since March 2011. In CFSv2, the ocean model is the GFDL MOM version 4 , which is configured for the global ocean with a horizontal grid of $0.5^{\circ} \mathrm{x} 0.5^{\circ}$ poleward of $30^{\circ} \mathrm{S}$ and $30^{\circ} \mathrm{N}$ and meridional resolution increasing gradually to $0.25^{\circ}$ between $10^{\circ} \mathrm{S}$ and $10^{\circ} \mathrm{N}$. The vertical coordinate is geopotential (z-) with 40 levels ( 27 of them in the upper $400 \mathrm{~m}$ ), with maximum depth of approximately $4.5 \mathrm{~km}$. The atmospheric model is the global forecast system (GFS), which has horizontal resolution of T126 (105-km grid spacing, a coarser resolution than is used for the GFS operational weather forecast), and 64 vertical levels in a hybrid sigma-pressure coordinate. The oceanic and atmospheric components exchange surface momentum, heat and freshwater fluxes, as well as SST, every 30 minutes. More details about CFSv2 can be found in ${ }^{27}$.

ECMWF Ocean ReAnalysis System 4 (ORAS4). ORAS4 ${ }^{30}$ is a state-of-the-art multivariate analysis system, which assimilates different types of temperature and salinity (T/S) profiles: XBTs (T only), Conductivity-Temperature-Depth sensors (CTDs, T/S), TAO/TRITON/PIRATA/RAMA moorings (T/S), Argo profilers (T/S), and Autonomous Pinniped Bathythermograph (APBs or elephant seals, T/S). Altimeter-derived sea level data (both anomalies and trends) are also assimilated.
Details about ORAS4 are referred to ${ }^{30}$. When compared with other reanalysis products, ORAS4 and its earlier non-operational version, COMBINE-NEMOVAR ${ }^{31}$ have merits in representing the tropical Atlantic variability ${ }^{32}$ and the initialization of ENSO prediction ${ }^{33}$. The salinity field in ORAS4 has been validated against climatologies and in-situ salinity observations ${ }^{30}$. Although the ORAS4 salinity field is found to be more uncertain than the temperature field, its mean state and variability is improved with respect to ocean-only simulations.

Verifying data. The observation-based monthly SST analysis used for validation is from the optimum interpolation analysis, version 2 (OIv2) SST dataset ${ }^{34}$, which has a resolution of $1.0^{\circ} \times 1.0^{\circ}$. The SSS validation data are from ORAS $4^{30}$

Hindcast experiments. The ocean initial conditions (OICs) are based on the instantaneous ocean states (restart files) from ECMWF ORAS $4^{30}$. For each OIC, four ensemble members are generated by changing the atmospheric and land initial conditions, using the instantaneous fields from $00 \mathrm{Z}$ of the first four days in April of each year in the NCEP Climate Forecast System Reanalysis $\left(\mathrm{CFSR}^{35}\right)$. The experimental predictions are produced for up to 12 months lead time from April to the following March for the period 1982-2009. This set of forecasts is referred to as the CTL experiment. In our previous study ${ }^{33}$, it was demonstrated that CTL has good skill in predicting the SST in the tropical Pacific. To explore the effect of interannually varying salinity on ENSO prediction, the initial salinity states in experiment CTL were replaced with the ORAS4 salinity climatology based on 1982-2009. This set of forecasts is referred to as the noS experiment. Note that in the noS experiment realistic and climatological salinity distributions are still included in the initial states, which is in contrast to some previous experiments where salinity was totally neglected or held constant in each model level ${ }^{9-11}$. The forecast anomalies in CTL and noS are computed with respect to their respective hindcast climatologies, and most analyses are based on the ensemble mean.

1. Cane, M. A., Zebiak, S. E. \& Dolan, S. C. Experimental forecast of El Niño. Nature 321, 827-832 (1986).

2. Bjerknes, J. Atmospheric teleconnections from the equatorial Pacific. Mon. Wea. Rev. 97, 163-172 (1969).

3. Wyrtki, K. El Niño--the dynamic response of the equatorial Pacific Ocean to atmospheric forcing. J. Phys. Oceanogr. 5, 572-584 (1975).

4. Suarez, M. J. \& Schopf, P. S. A delayed action oscillator for ENSO. J. Atmos. Sci. 45, 3283-3287 (1988). 
5. Battisti, D. S. \& Hirst, A. C. Interannual variability in the tropical atmosphereocean model: influence of the basic state, ocean geometry and nonlineary. J. Atmos. Sci. 45, 1687-1712 (1989).

6. Jin, F. F. An equatorial ocean recharge paradigm for ENSO. Part I: Conceptual model. J. Atmos. Sci. 54, 811-829 (1997).

7. Rasmusson, E. \& Carpenter, T. Variations in tropical sea surface temperature and surface wind fields associated with the Southern Oscillation/El Niño. Mon. Wea. Rev. 110, 354-384 (1982).

8. McPhaden, M. Genesis and evolution of the 1997-98 El Niño. Science 283, 950-954 (1999).

9. Cooper, N. S. The Effect of salinity on tropical ccean models. J. Phys. Oceanogr. 18, 697-707 (1988).

10. Murtugudde, R. \& Busalacchi, A. J. Salinity effects in a tropical ocean model. J. Geophys. Res. 103, 3283-3300 (1998).

11. Vialard, J., Delecluse, P. \& Menkes, C. A modeling study of salinity variability and its effects in the tropical Pacific Ocean during the 1993-1999 period. J. Geophys. Res. 107, 8005 (2002).

12. Maes, C., Picaut, J. \& Belamari, S. Salinity barrier layer and onset of El Niño in a Pacific coupled model. Geophys. Res. Lett. 29, 2206 (2002).

13. Maes, C., Picaut, J. \& Belamari, S. Importance of salinity barrier layer for the buildup of El Niño. J. Climate 18, 104-118 (2005).

14. Zhang, R.-H. \& Busalacchi, A. J. Freshwater flux (FWF)-induced oceanic feedback in a hybrid coupled model of the tropical Pacific. J. Climate 22, 853-879 (2009).

15. Zheng, F. \& Zhang, R.-H. Effects of interannual salinity variability and freshwater flux forcing on the development of the 2007/08 La Niña event diagnosed from Argo and satellite data. Dyn. Atmos. Oceans 57, 45-57 (2012).

16. Brown, J. N. et al. Reinvigorating Research on the Western Pacific Warm Pool First Workshop. CLIVAR Exchanges newsletter, No. 63 (2013).

17. Picaut, J., Ioualalen, M., Menkes, C., Delcroix, T. \& McPhaden, M. Mechanism of the zonal displacements of the Pacific warm pool, implications for ENSO. Science 274, 1486-1489 (1996).

18. Delcroix, T. \& McPhaden, M. Interannual sea surface salinity and temperature changes in the western Pacific warm pool during 1992-2000. J. Geophys. Res. 107, 8002 (2002)

19. Maes, C., McPhaden, M. \& Behringer, D. Signatures of salinity variability in tropical Pacific Ocean dynamic height anomalies. J. Geophys. Res. 107, 8012 (2002)

20. Ji, M., Reynolds, R. W. \& Behringer, D. Use of TOPEX/Poseidon sea level data for ocean analyses and ENSO predictions: Some early results. J. Climate 13, 216-231 (2000).

21. Ballabrera-Poy, J., Murtugudde, R. \& Busalacchi, A. J. On the potential impact of sea surface salinity observations on ENSO predictions. J. Geophys. Res. 107, 8007 (2002).

22. Hackert, E., Ballabrera-Poy, J., Busalacchi, A. J., Zhang, R.-H. \& Murtugudde, R. G. Impact of sea surface salinity assimilation on coupled forecasts in the tropical Pacific. J. Geophys. Res. 116, C05009 (2011).

23. Zhao, M., Hendon, H., Alves, O., Yin, Y. \& Anderson, D. Impact of Salinity Constraints on the Simulated Mean State and Variability in a Coupled Seasonal Forecast Model. Mon. Wea. Rev. 141, 388-402 (2013).

24. Zhao, M., Hendon, H., Alves, O. \& Yin, Y. Impact of improved assimilation of temperature and salinity for coupled model seasonal forecasts. Clim. Dyn. 42, 2565-2583 (2014).

25. Zhang, R.-H., Zebiak, S. E., Kleeman, R. \& Keenlyside, N. A new intermediate coupled model for El Niño simulation and prediction. Geophys. Res. Lett. 30, 2012 (2003).

26. Latif, M. et al. A review of the predictability and prediction of ENSO. J. Geophys. Res. 103, 14 375-14 393 (1998).
27. Saha, S. et al. The NCEP Climate Forecast System Version 2. J. Climate 27, 2185-2208 (2014).

28. Barnston, A. G., Chelliah, M. \& Goldenberg, S. B. Documentation of a Highly ENSO-Related SST Region in the Equatorial Pacific. Atmosphere-Ocean 35 367-383 (1997).

29. Argo Science Team Argo: The global array of profiling floats, in Observing the Oceans in the 21st Century, C. J. Koblinsky and N. R. Smith, eds., GODAE Project Office, Bureau of Meteorology, Melbourne, 248-258 (2001).

30. Balmaseda, M., Mogensen, K. \& Weaver, A. Evaluation of the ECMWF ocean reanalysis ORAS4. Quart. J. Roy. Meteor. Soc. 139, 1132-1161 (2013).

31. Balmaseda, M., Mogensen, K., Molteni, F. \& Weaver, A. The NEMOVARCOMBINE ocean re-analysis. COMBINE Technical Report No. 1. (2010). http:// www.combine-project.eu/fileadmin/user_upload/combine/tech_report/ COMBINE_TECH_REP_n01.pdf. Date of access: 12/09/2014.

32. Zhu, J., Huang, B. \& Balmaseda, M. A. An ensemble estimation of the variability of upper-ocean heat content over the tropical Atlantic Ocean with multi-ocean reanalysis products. Clim. Dyn. 39, 1001-1020 (2012).

33. Zhu, J. et al. Ensemble ENSO hindcasts initialized from multiple ocean analyses. Geophys. Res. Lett. 39, L09602 (2012).

34. Reynolds, R. W., Rayner, N. A., Smith, T. M., Stokes, D. C. \& Wang, W. An improved in situ and satellite SST analysis for climate. J. Climate 15, 1609-1625 (2002).

35. Saha, S. et al. The NCEP Climate Forecast System Reanalysis. Bull. Amer. Meteor Soc. 91, 1015-1057 (2010).

\section{Acknowledgments}

We would like to thank Profs. J. M. Wallace and J. Shukla for their constructive comments and insightful suggestions. Funding for this study is provided by grants from NSF (ATM-0830068), NOAA (NA09OAR4310058), and NASA (NNX09AN50G). R.Z. is supported by the National Basic Research Program of China (Project 2012CB956000), the CAS Strategic Priority Project (the Western Pacific Ocean System, WPOS), and by the Institute of Oceanology, Chinese Academy of Sciences (IOCAS). Computing resources provided by NAS are also gratefully acknowledged.

\section{Author contributions}

J.Z. and B.H. designed the experiments and performed the data analysis. J. Z. made all plots and wrote the initial draft of the paper. All authors (J.Z., B.H., R.Z., Z.H., A.K., M.B., L.M. and J.K.) contributed to interpreting results and improvement of this paper.

\section{Additional information}

Supplementary information accompanies this paper at http://www.nature.com/ scientificreports

Competing financial interests: The authors declare no competing financial interests.

How to cite this article: Zhu, J. et al. Salinity anomaly as a trigger for ENSO events. Sci. Rep. 4, 6821; DOI:10.1038/srep06821 (2014).

This work is licensed under a Creative Commons Attribution-NonCommercialNoDerivs 4.0 International License. The images or other third party material in this article are included in the article's Creative Commons license, unless indicated otherwise in the credit line; if the material is not included under the Creative Commons license, users will need to obtain permission from the license holder in order to reproduce the material. To view a copy of this license, visit http:// creativecommons.org/licenses/by-nc-nd/4.0/ 